\title{
Repeated intermittent administration of $(R)$-ketamine during juvenile and adolescent stages prevents schizophrenia-relevant phenotypes in adult offspring after maternal immune activation: a role of TrkB signaling
}

\author{
Yunfei Tan ${ }^{1} \cdot$ Yuko Fujita $^{1} \cdot$ Yaoyu Pu ${ }^{1} \cdot$ Lijia Chang $^{1} \cdot$ Youge $^{Q^{1}}{ }^{1} \cdot$ Xinming Wang $^{1} \cdot$ Kenji Hashimoto $^{1}(\mathbb{C}$
}

Received: 11 October 2021 / Accepted: 24 November 2021 / Published online: 3 January 2022

(c) The Author(s) 2021

\begin{abstract}
Maternal immune activation (MIA) plays a role in the etiology of schizophrenia. MIA by prenatal exposure of polyinosinic:polycytidylic acid [poly(I:C)] in rodents caused behavioral and neurobiological changes relevant to schizophrenia in adult offspring. We investigated whether the novel antidepressant $(R)$-ketamine could prevent the development of psychosis-like phenotypes in adult offspring after MIA. We examined the effects of $(R)$-ketamine $(10 \mathrm{mg} / \mathrm{kg} / \mathrm{day}$, twice weekly for 4 weeks) during juvenile and adolescent stages (P28-P56) on the development of cognitive deficits, loss of parvalbumin (PV)-immunoreactivity in the medial prefrontal cortex (mPFC), and decreased dendritic spine density in the mPFC and hippocampus from adult offspring after prenatal poly(I:C) exposure. Furthermore, we examined the role of TrkB in the prophylactic effects of $(R)$-ketamine. Repeated intermittent administration of $(R)$-ketamine during juvenile and adolescent stages significantly blocked the development of cognitive deficits, reduced PV-immunoreactivity in the prelimbic (PrL) of $\mathrm{mPFC}$, and decreased dendritic spine density in the PrL of mPFC, CA3 and dentate gyrus of the hippocampus from adult offspring after prenatal poly(I:C) exposure. Furthermore, pretreatment with ANA-12 (TrkB antagonist: twice weekly for 4 weeks) significantly blocked the beneficial effects of $(R)$-ketamine on cognitive deficits of adult offspring after prenatal poly(I:C) exposure. These data suggest that repeated intermittent administration of $(R)$-ketamine during juvenile and adolescent stages could prevent the development of psychosis in adult offspring after MIA. Therefore, $(R)$-ketamine would be a potential prophylactic drug for young subjects with high-risk for psychosis.
\end{abstract}

Keywords Cognitive deficits $\cdot$ Psychosis $\cdot$ Prevention $\cdot(R)$-ketamine $\cdot \operatorname{TrkB}$

\section{Introduction}

Schizophrenia is a complex and heterogeneous psychiatric disorder that has significant economic, clinical and social impacts worldwide. The range of symptoms of schizophrenia includes positive symptoms (i.e., delusions, hallucinations, thinking disorders), negative symptoms (i.e., anhedonia, depression, social withdrawal, flawed thinking), and cognitive impairment (i.e., attention, memory, processing speed). Cognitive impairment is the core symptom in patients with schizophrenia that is present across the course of the illness

Kenji Hashimoto

hashimoto@faculty.chiba-u.jp

1 Division of Clinical Neuroscience, Chiba University Center for Forensic Mental Health, Chiba 260-8670, Japan
[1-3]. Increasing evidence shows that cognitive impairment is detected in childhood and adolescence prior to the onset of psychosis [4-6]. A meta-analysis shows that cognitive impairment in people at clinical high risk for psychosis who converted to psychosis was greater than in those who did not convert to psychosis [7]. Collectively, it is important to treat cognitive impairment in young subjects with ultra-high risk for psychosis [8].

Multiple epidemiological studies suggest that maternal immune activation (MIA) such as viral infection during pregnancy plays a role in the etiology of schizophrenia [9-11]. MIA using polyriboinosinic-polyribocytidilic acid [poly(I:C)], a Toll-like receptor 3 agonist, has been widely used as an animal model for schizophrenia since adult offspring after prenatal poly(I:C) exposure show behavioral abnormalities relevant to schizophrenia [12-17]. 
Interestingly, cognitive impairment is detected before the onset of schizophrenia, suggesting the potential benefit of early intervention in the prodromal symptoms of young adults with a high risk for psychosis [8]. We previously found cognitive deficits of juvenile offspring from poly(I:C)treated pregnant mice, suggesting that juvenile offspring after MIA may be a prodromal stage for schizophrenia [18-21].

$(R, S)$-ketamine, an $N$-methyl-D-aspartate receptor (NMDAR) antagonist, is an equal mixture of $(R)$-ketamine and $(S)$-ketamine. We demonstrated that $(R)$-ketamine, enantiomer of $(R, S)$-ketamine, has greater potency and longerlasting antidepressant-like effects than $(S)$-ketamine in animal models of depression despite lower affinity at NMDAR [22-28]. Interestingly, side effects of $(R)$-ketamine in rodents, monkey and humans were less than $(R, S)$-ketamine and $(S)$-ketamine [23, 29-35]. Collectively, $(R)$-ketamine would be a novel antidepressant without detrimental side effects of $(R, S)$-ketamine [36-41].

The NMDAR antagonist phencyclidine (PCP) has been widely used as an animal model of schizophrenia since PCP caused schizophrenia-like symptoms in humans [42-45]. We reported that PCP-induced cognitive deficits in mice were ameliorated by subsequent repeated intermittent administration of $(R)$-ketamine, but not $(S)$-ketamine [46]. Furthermore, ANA-12 (TrkB antagonist) blocked the beneficial effects of $(R)$-ketamine in PCP model [46], suggesting a role of TrkB in the beneficial effects of $(R)$-ketamine. However, there are no reports investigating the effect of $(R)$-ketamine in MIA model.

In this study, we investigated whether repeated intermittent administration of $(R)$-ketamine during juvenile and adolescent stages could prevent the development of cognitive deficits, reduced immunoreactivity of parvalbumin (PV) and dendritic spine density in the medial prefrontal cortex (mPFC) in adult offspring after maternal poly(I:C) exposure. Furthermore, we examined the effects of ANA-12 in the beneficial effects of $(R)$-ketamine in the MIA model since brainderived neurotrophic factor (BDNF) and its receptor TrkB signaling could play a role in the pharmacological effects of $(R)$-ketamine $[23,46-50]$.

\section{Methods and materials}

\section{Animals and poly(l:C) injection}

Pregnant female mice ddY (5 days) were purchased from SLC Company Japan (Hamamatsu, Shizuoka, Japan). The pregnant mice were intraperitoneally (i.p.) injected with poly(I:C) $(5.0 \mathrm{mg} / \mathrm{kg} /$ day from E12 to E17) or an equivalent volume of saline as previously reported [18-21]. The offspring were separated from their mother mice at 3-weeks old, and male mice were kept in cages in groups of three to five. The mice were housed in a $22.5 \times 33.8 \times 14.0 \mathrm{~cm}$ transparent Polycarbonate cage, at a room temperature of $23 \pm 1{ }^{\circ} \mathrm{C}$, a humidity of $55 \pm 5 \%$, and the controlled light-dark cycle was 12/12 h (lights on from 07:00 a.m. to 07:00 p.m.), with ad libitum food (CE-2; CLEA Japan, Inc., Tokyo, Japan) and water. All experiments were performed in accordance with the animal experiment guidelines of Chiba University. The protocol (permission number: 1-331 and 2-131) was approved by the Institutional Animal Care and Use Committee of Chiba University.

\section{Drugs}

Poly(I:C) was purchased from CALBIOCHEM (San Diego, CA, USA). $(R)$-ketamine hydrochloride was prepared in our laboratory, as previously reported [22]. ANA-12 (N-[2[[(Hexahydro-2-oxo-1H-azepin-3-yl)amino]carbonyl] phenyl]-benzo[b]thiophene-2-carboxamide: $0.5 \mathrm{mg} / \mathrm{kg}$ ) (Sigma-Aldrich Japan, Tokyo, Japan) was dissolved in phosphate-buffered saline (PBS) containing 17\% dimethyl sulfoxide (DMSO) as previously reported [25, 46, 47, 51-54]. Other drugs are purchased from commercial sources.

\section{Drug administration}

Saline $(10 \mathrm{ml} / \mathrm{kg} /$ day, twice a week, for 4 weeks) or $(R)$ ketamine $(10 \mathrm{mg} / \mathrm{kg} /$ day as hydrochloride salt, twice a week, for 4 weeks) was administrated i.p. into male offspring (Fig. 1A). In the experiment using TrkB inhibitor ANA-12, the vehicle $(10 \mathrm{ml} / \mathrm{kg})$ or ANA-12 $(0.5 \mathrm{mg} / \mathrm{kg})$ was injected i.p. $30 \mathrm{~min}$ before saline $(10 \mathrm{ml} / \mathrm{kg} /$ day $)$ or $(R)$-ketamine (10 mg/kg/day) (Fig. 4A).

\section{Novel object recognition test (NORT)}

To assess cognitive function in mice, NORT was performed as previously reported [18-21, 46, 55]. Each mouse was allowed to habituate in the field for $10 \mathrm{~min}$ a day to adapt to the experimental equipment for 3 consecutive days. During the training process, two novel objects (different in shape and color, but similar in size) were placed in a box $35.5 \mathrm{~cm}$ apart (symmetrically), and each mouse was allowed to explore freely in this open field for $10 \mathrm{~min}$. When the mouse's head touches or stands on an object, the mouse is considered to be exploring the object. The time the mouse explored each object was recorded. After the training, the mice were immediately returned to their cages, and the boxes and objects were washed with $75 \%$ ethanol to avoid any possible instinctive odor cues. $24 \mathrm{~h}$ after training, the retention test was performed in the same box, and one of the familiar objects was replaced by a new object during the retention session. Then let the mice explore freely for $5 \mathrm{~min}$ 


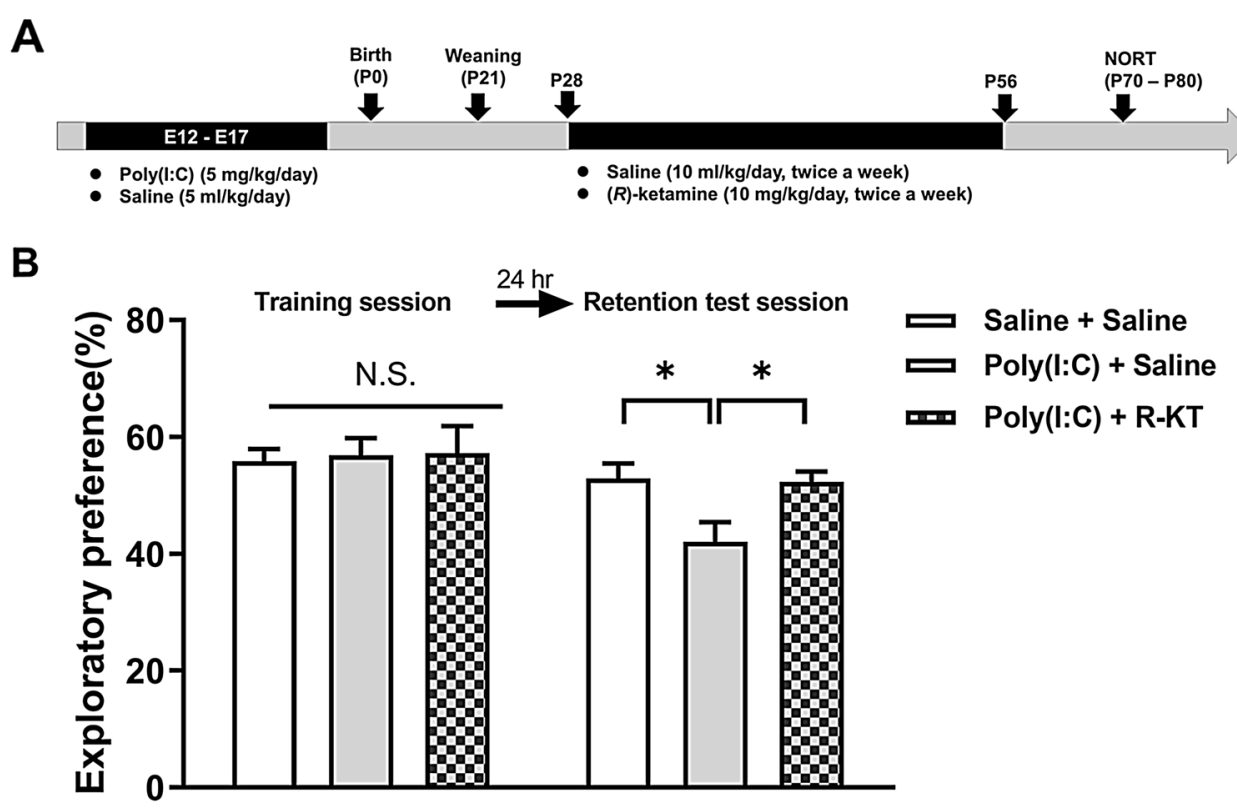

Fig. 1 Effects of $(R)$-ketamine on cognitive deficits in adult offspring after prenatal poly(I:C) exposure. A Schedule of treatment and behavioral tests. Saline $(5.0 \mathrm{ml} / \mathrm{kg} /$ day $)$ or poly(I:C) $(5.0 \mathrm{mg} / \mathrm{kg} /$ day from E12 to E17) was injected i.p. into pregnant mice. Male offspring was separated from mothers on P21. Saline $(10 \mathrm{ml} / \mathrm{kg} /$ day, twice a week) or $(R)$-ketamine $(10 \mathrm{mg} / \mathrm{kg} / \mathrm{day}$, twice a week) was administered i.p. to male offspring from P28 to P56. Novel object recognition test

and record the time spent exploring each object. Throughout the experiment, these objects are balanced in terms of physical complexity and emotional neutrality. The preference index, which is the ratio of the time spent exploring two objects (training session) or a new object (retention test session) to the total time spent exploring two objects, is used to measure recognition memory.

\section{PV-immunohistochemistry}

Immunohistochemistry of PV in the mouse brain was performed, as previously reported [19, 21]. Mice were deeply anesthetized with pentobarbital sodium, and $10 \mathrm{~mL}$ of isotonic saline was added, followed by $40 \mathrm{~mL}$ of cold $4 \%$ paraformaldehyde $0.1 \mathrm{M}$ phosphate buffer ( $\mathrm{pH}$ 7.4). The brain was removed from the skull and immobilized overnight at $4{ }^{\circ} \mathrm{C}$ in the same fixator. For immunohistochemical analysis, continuous sections of coronal brain tissue $50 \mu \mathrm{m}$ thick were cut using a vibrating blade micro slicer (VT1000S, Leica Microsystems AG, Wetzlar, Germany) in a cold $0.01 \mathrm{M}$ phosphate buffer ( $\mathrm{pH}$ 7.5). Free-floating sections were treated with $0.3 \% \mathrm{H}_{2} \mathrm{O}_{2}$ in $50 \mathrm{mM}$ Tris $-\mathrm{HCl}$ saline (TBS) for $30 \mathrm{~min}$ and sealed in TBS containing $0.2 \%$ Triton $\mathrm{X}-100$ (TBST) and $1.5 \%$ normal goat serum for $1 \mathrm{~h}$ at room temperature. The sample was then incubated with rabbit polyclonal anti-PV antibodies (1:2,500, Swant, Bellinzona,
(NORT) was performed from P70-P80. Brain samples for PV-immunohistochemistry were collected at P80. B NORT: There was no difference between the three groups in the training session. In the retention session, the exploratory preference of poly $(\mathrm{I}: \mathrm{C})+$ saline group was significantly lower than vehicle + saline-treated group. $* P<0.01$ compared with poly(I:C) + saline-treated group. N.S.: not significance. The value is expressed as the mean \pm S.E.M. $(n=8)$

Switzerland) at $4{ }^{\circ} \mathrm{C}$ for $24 \mathrm{~h}$. Sections were washed three times in TBS, and then the avidin-biotin-peroxidase method was used (Vectastain Elite ABC, Vector Laboratories, Inc., Burlingame, CA, USA). Sections were incubated in $0.25 \mathrm{mg} /$ $\mathrm{mL}$ diaminobenzidine solution containing $0.01 \% \mathrm{H}_{2} \mathrm{O}_{2}$ for $3 \mathrm{~min}$. The slides were then installed on the gelatinized glass slide, dehydrated, cleaned, and covered with cover glass (Fisher Scientific, Fair Lawn, NJ, USA). The sections were imaged, and the staining intensity of PV-immunoreactivity in the infralimbic (IL) and prelimbic (PrL) of the medial prefrontal cortex (mPFC), and CA1, CA3 and dentate gyrus (DG) of hippocampus was analyzed using an optical microscope equipped with a CCD camera (Olympus IX70, Tokyo, Japan) and the SCION IMAGE software package. Images of sections within brain regions were captured using a $100 \times$ objective with a Keyence BZ-9000 Generation II microscope (Osaka, Japan).

\section{Golgi staining}

For Golgi staining in the brain, FD Rapid GolgiStain ${ }^{\mathrm{TM}} \mathrm{Kit}$ (FD Neuro Technologies, Inc., Columbia, MD) was used as reported previously $[23,54,56,57]$. The mice were deeply anesthetized with sodium pentobarbital. The brain was removed from the skull and rinsed with double distilled water. Golgi staining of the brain and preparation of brain 
sections were performed at Biopathology Institute Co., Ltd (Kunisaki, Oita, Japan). Brain regions such as mPFC, CA1, CA3, DG of hippocampus were taken under a Keyence BZ-9000 Generation II Microscope (Osaka, Japan) with a $100 \times$ objective lens. The number of dendritic spine density in the brain regions was counted. For spine density measurement, the clear and assessable areas were used, including the $50-100 \mu \mathrm{m}$ of the secondary dendrites of each imaged neuron. To determine the relative spine densities, we counted the number of spines of multiple dendritic branches of a single neuron to obtain the average number of ranges per $10 \mu \mathrm{m}$. For the number of spines measured, only those spines that appear perpendicular to the dendritic axis are counted. We analyzed 3 parts of each neuron and 3 parts of each animal.

\section{Statistical analysis}

The data are shown as the mean \pm standard error of the mean (SEM). The analysis was performed using PASW Statistics 20 (formerly SPSS Statistics; SPSS, Tokyo, Japan). Data including the NORT, immunohistochemistry results, and dendritic spine density, were analyzed by one-way analysis of variance (ANOVA), followed by post-hoc Tukey HSD test. A $P$ value of less than 0.05 was considered statistically significant.

\section{Results}

\section{Prophylactic effects of (R)-ketamine on cognitive deficits in adult offspring of prenatal exposure of poly(l:C)}

In NORT, the repeated administration of poly(I:C) $(5 \mathrm{mg} /$ $\mathrm{kg} /$ day for 6 days) during E12 to E17 caused cognitive deficits in adult offspring (Fig. 1B). In the training session, there was no difference (one-way ANOVA: $F_{2,21}=0.040$, $P=0.961$ ) among the three groups (Fig. 1B). In the retention test session, there was a significant difference (one-way ANOVA: $\left.F_{2,21}=5.330, P<0.05\right)$ among the three groups. The repeated intermittent administration of $(R)$-ketamine $(10 \mathrm{mg} / \mathrm{kg} /$ day, twice a week, 4 weeks) significantly ameliorated the decreased exploratory preference in adult offspring after prenatal poly(I:C) exposure (Fig. 1B).

\section{Effects of (R)-ketamine on decreased PV-immunoreactivity in the MPFC of adult offspring after prenatal poly $(\mathrm{I}: \mathrm{C})$ exposure}

We previously reported that reduction of PV-positive cells in the mPFC might be associated with cognitive deficits in offspring after MIA [19]. We performed PV-immunohistochemistry in the mPFC from adult offspring after MIA

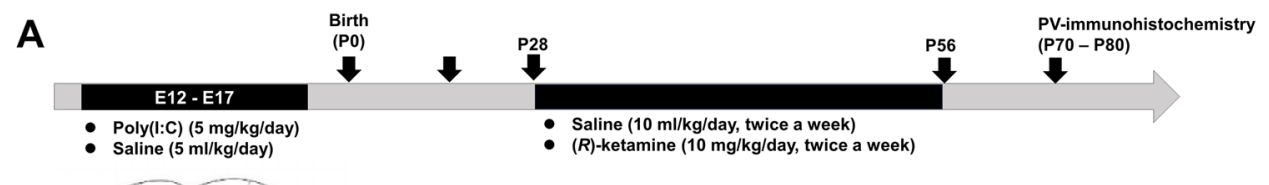

A

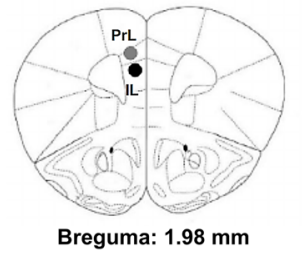

C

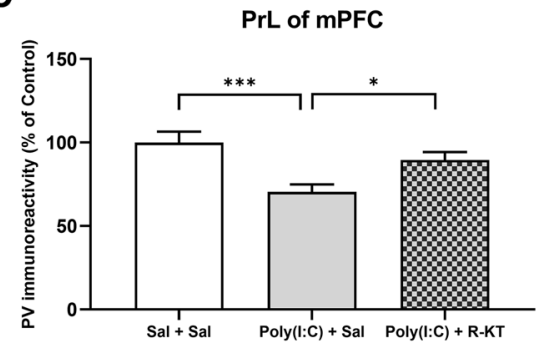

Fig. 2 Effects of $(R)$-ketamine on decreased PV-immunoreactivity in the mPFC of adult offspring after prenatal poly(I:C) exposure. A Brain atlas of prelimbic (PrL) area and infralimbic (IL) area of the medial prefrontal cortex (mPFC). B Representative data of PV-immunoreactivity in the mPFC of adult offspring after MIA. C The PVimmunoreactivity in the PrL of mPFC of poly(I:C)+ saline-treated

B

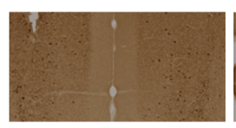

Saline + Saline

D

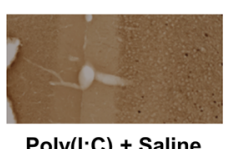

Poly(I:C) + Saline

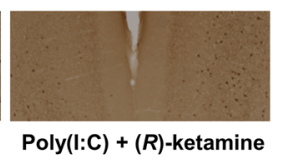

IL of mPFC

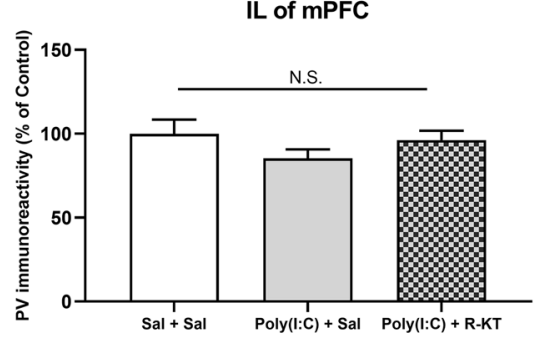

group was significantly lower than that of other two groups. D There were no changes for PV-immunoreactivity in the IL among the three groups. $* P<0.05$, $* * * P<0.001$, compared with poly(I:C) + salinetreated group. N.S.: not significance. The value is expressed as the mean \pm S.E.M. $(n=10)$ 
(Fig. 2A). One-way ANOVA analysis revealed significant effects (PrL: $F_{2,27}=7.927, P<0.001$ ) among the three groups (Fig. 2C). The post-hoc test showed that PV-immunoreactivity in the PrL of mPFC of poly(I:C) + saline group was significantly lower than that of vehicle + vehicle group or poly(I:C) $+(R)$-ketamine groups (Fig. $2 \mathrm{C}$ ). In contrast, one-way ANOVA analysis of IL data revealed no significant effects (IL: $F_{2,27}=1.311, P=0.227$ ) among the three groups (Fig. 2D). These findings suggest that adult offspring after prenatal poly(I:C) exposure showed the loss of PVimmunoreactivity in the PrL of mPFC, but not IL, and that repeated intermittent administration of $(R)$-ketamine could prevent the loss of PV-immunoreactivity in the PrL of mPFC of adult offspring after prenatal poly(I:C) exposure.

\section{Effects of (R)-ketamine on dendritic spine density in the brain of adult offspring after prenatal poly(I:C) exposure}

Dendritic spine density measurement was performed in adulthood offspring after MIA. One-way ANOVA analysis revealed that dendritic spine densities in the PrL region of the $\mathrm{mPFC}, \mathrm{CA} 3$ and $\mathrm{DG}$ regions of the hippocampus from adult offspring after prenatal poly(I:C) exposure were statistically significant (PrL: $F_{2,21}=22.97, P<0.001$; CA3: $F_{2,21}=23.80, P<0.001$; DG: $F_{2,21}=12.22, P<0.001$ ) among the three groups (Fig. 3B, E, F). The post-hoc test showed that dendritic spine density in the PrL of mPFC, CA3 and DG of the hippocampus from poly(I:C) + saline group was significantly lower than that of saline + saline group or poly (I:C) $+(R)$-ketamine group (Fig. 3B, E, F). In contrast, one-way ANOVA analysis revealed that dendritic spine densities in the IL regions of the MPFC, CA1 region of the hippocampus from the adult offspring after prenatal poly(I:C) exposure were not statistically significant (IL: $F_{2,21}=0.1132, P=0.894$; CA1: $F_{2,21}=2.829, P=0.082$ ) among the three group (Fig. 3C, D). These findings suggest that adult offspring after prenatal poly(I:C) exposure showed the decreased spine density in the PrL of mPFC, CA3 and DG of the hippocampus, and that repeated intermittent administration of $(R)$-ketamine could ameliorate the decreased spine density in these brain regions after MIA.

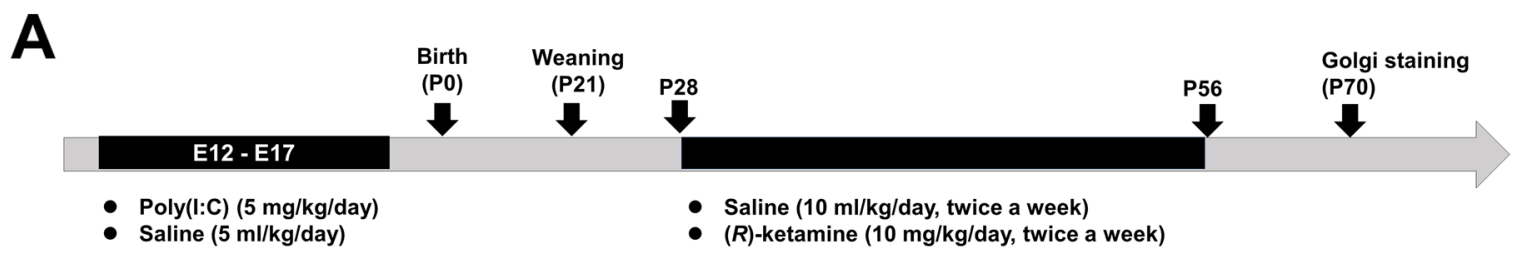

B
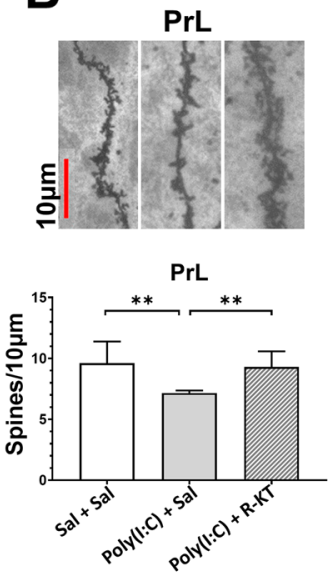

C
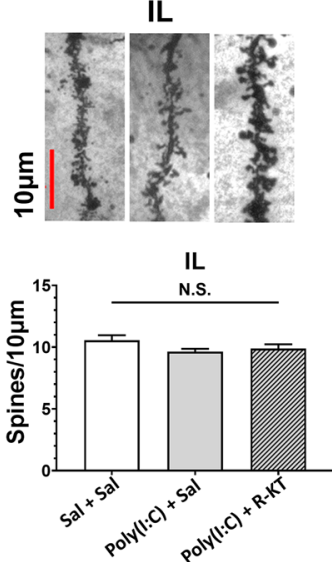

D
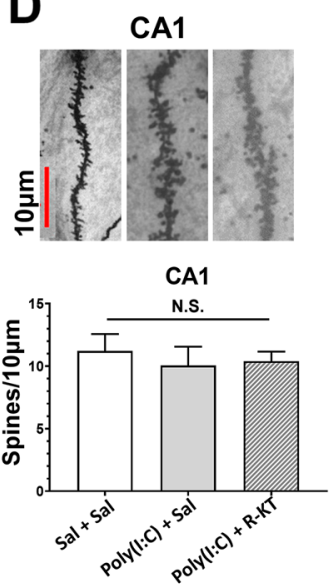

E

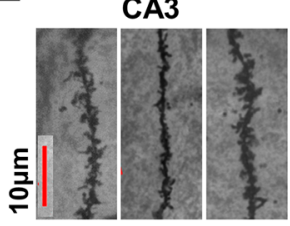

CA3

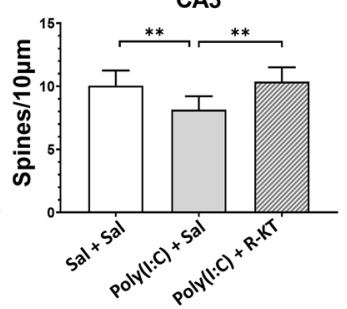

$\mathbf{F}$

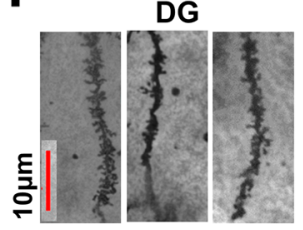

DG

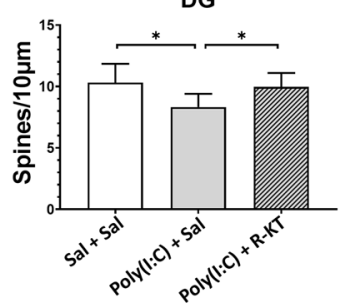

Fig. 3 Effects of $(R)$-ketamine on dendritic spine density in the brain of adult offspring after prenatal poly(I:C) exposure. A Schedule of treatment and behavioral tests. Saline $(5.0 \mathrm{ml} / \mathrm{kg} / \mathrm{day})$ or poly(I:C) $(5.0 \mathrm{mg} / \mathrm{kg} /$ day from E12 to E17) was injected i.p. into pregnant mice. Male offspring was separated from mothers on P21. Saline $(10 \mathrm{ml} / \mathrm{kg} /$ day, twice a week $)$ or $(R)$-ketamine $(10 \mathrm{mg} / \mathrm{kg} /$ day, twice a week) was administered i.p. to male offspring from P28 to P56. Brain samples for Golgi staining were collected at P70. B-F Repre- sentative images of Golgi staining in the MPFC and hippocampus of adult offspring after MIA. The number of dendritic spine density in the PrL of mPFC, CA3, and DG of poly(I:C) + saline-treated group was significantly lower than that of the other two groups. In contrast, there were no changes for spine density in the PL and CA1 among the three groups. ${ }^{*} P<0.05$, compared with poly(I:C) + saline group. $* * P<0.01$, compared with poly(I:C) + saline group. N.S.: not significance. The value is expressed as the mean \pm S.E.M. $(n=8)$ 


\section{Effects of ANA-12 in the effects of (R)-ketamine on cognitive deficits in adult offspring after prenatal poly(I:C) exposure}

To examine the role of TrkB signaling pathway in the prophylactic action of $(R)$-ketamine, we investigated the effects of the TrkB inhibitor ANA-12 in the juvenile offspring of prenatal mice exposed to poly(I:C) (Fig. 4A). In the training session, there were no significant differences (one-way ANOVA: $F_{4.52}=0.9507, P=0.442$ ) between the five groups (Fig. 4B). In the retention test session, there were significant differences (one-way ANOVA: $F_{4,52}=4.305, P<0.01$ ) between the five groups (Fig. 4B). The pretreatment with ANA-12 significantly antagonized the beneficial effects of $(R)$-ketamine in the offspring of prenatal mice exposed to poly(I:C) (Fig. 4B). In contrast, ANA-12 alone did not improve MIA-induced cognitive deficits (Fig. 4B).

\section{Discussion}

The major findings of the present study are as follows. Repeated intermittent administration of $(R)$-ketamine during the juvenile and adolescent stages could prevent the development of cognitive deficits, reduced PV-immunoreactivity in the PrL of mPFC and reduced dendritic spine density in the PrL of mPFC, CA3 and DG of the hippocampus of adult offspring after prenatal poly(I:C) exposure. Furthermore, pretreatment with ANA-12 blocked the beneficial effects of $(R)$-ketamine in this model. These data suggest that $(R)$-ketamine shows prophylactic effects in MIA model through TrkB activation. Therefore, it is likely that treatment with $(R)$-ketamine in subjects with ultra-high risk for psychosis might block the subsequent conversion to psychosis in young adulthood.

We found cognitive deficits of juvenile offspring in mice after prenatal poly(I:C) exposure [18-21], indicating cognitive deficits as prodromal symptoms. We reported that supplementation with TrkB receptor agonist 7,8-dihydroxyflavone $(1 \mathrm{mg} / \mathrm{mL}$ in drinking water) during juvenile and adolescent stages could prevent cognitive deficits as well as reduced BDNF-TrkB signaling in the PFC of adult offspring after MIA [19]. In this study, we found that pretreatment with ANA-12 blocked the prophylactic effects of $(R)$ ketamine in MIA-induced model. Collectively, it is likely that $(R)$-ketamine can exert beneficial effects by activating BDNF-TrkB signaling in the brain.

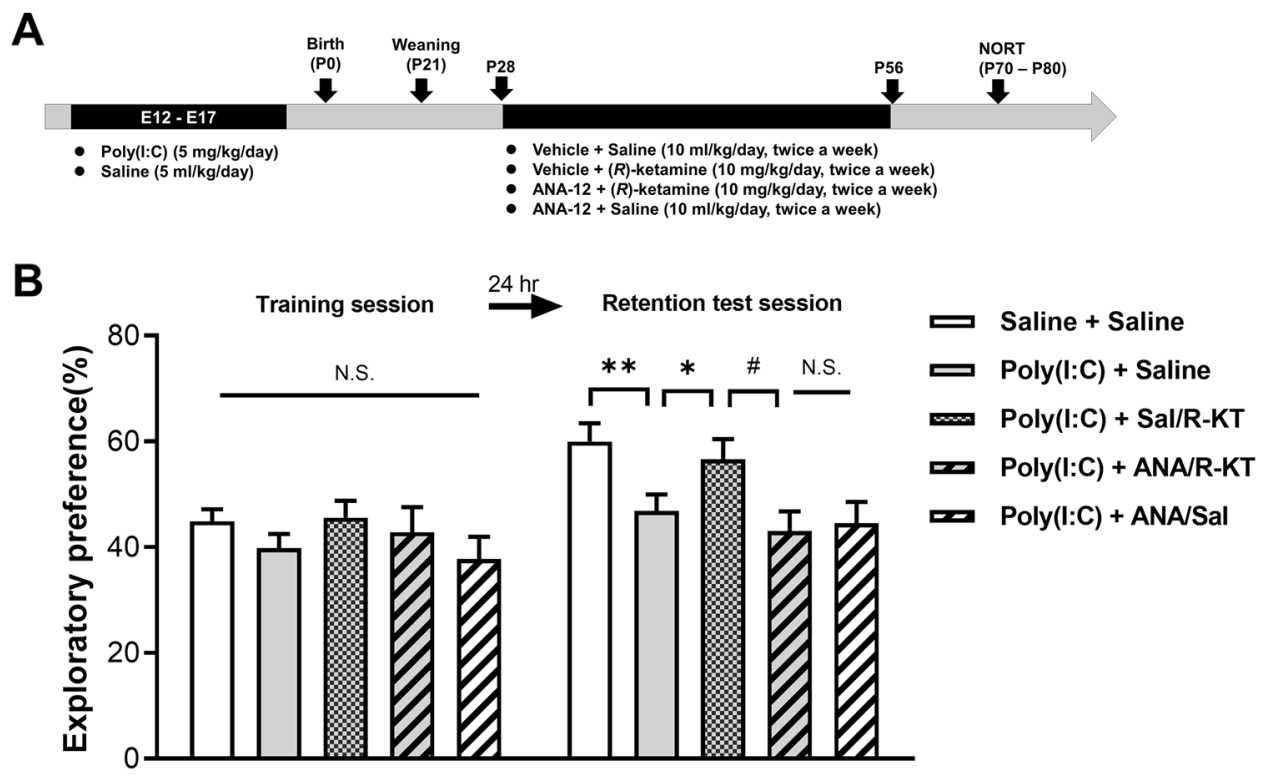

Fig. 4 Effects of ANA-12 on prophylactic effects of $(R)$-ketamine on cognitive deficits in adult offspring after prenatal poly(I:C) exposure. A: Schedule of treatment and behavioral tests. Saline $(5.0 \mathrm{ml} /$ $\mathrm{kg} /$ day) or poly(I:C) $(5.0 \mathrm{mg} / \mathrm{kg} /$ day from E12 to E17) was injected i.p. into pregnant mice. Male offspring was separated from mothers on P21. Saline $(10 \mathrm{ml} / \mathrm{kg} / \mathrm{day}$, twice a week) or $(R)$-ketamine $(10 \mathrm{mg} /$ $\mathrm{kg}$ /day, twice a week) was administered i.p. to male offspring from P28 to P56. Vehicle $(10 \mathrm{ml} / \mathrm{kg} /$ day $)$ or ANA-12 $(0.5 \mathrm{mg} / \mathrm{kg} /$ day $)$ was injected i.p. $30 \mathrm{~min}$ before injection of saline or $(R)$-ketamine. Novel object recognition test (NORT) was performed from P70-P80.
B: NORT: There was no difference between the five groups in the training session. In the retention test session, the exploratory preference of poly(I:C) + vehicle/saline group was significantly lower than saline + vehicle $/(R)$-ketamine group. The exploratory preference of poly $(\mathrm{I}: \mathrm{C})+\operatorname{vehicle} /(R)$-ketamine group was significantly higher than poly $(\mathrm{I}: \mathrm{C})+\mathrm{ANA} /(R)$-ketamine group. ${ }^{*} P<0.05$, $* * P<0.01$ compared to poly(I:C) + vehicle/saline group. ${ }^{\#} P<0.05$ compared to poly(I:C) + vehicle/ $(R)$-ketamine group. N.S.: not significance. The values were expressed as the mean \pm S.E.M. $(n=7-14)$ 
$(R, S)$-ketamine has been used widely as an animal model of schizophrenia since $(R, S)$-ketamine is reported to cause schizophrenia-like symptoms (i.e., positive and negative symptoms, and cognitive impairment) in healthy control subjects $[58,59]$. In contrast, a recent systematic review showed that subanesthetic dose of $(R, S)$-ketamine $(0.5 \mathrm{mg} / \mathrm{kg})$ showed significant improvements in cognitive impairment in treatment-resistant patients with depression, although $(R, S)$-ketamine did not worsen cognitive function in depressed patients $[41,60]$. Thus, it seems that the effects of $(R, S)$-ketamine on the cognition of healthy control subjects and patients with psychiatric disorders are not consistent. Importantly, it is reported that $(R)$-ketamine has less detrimental side effects than $(R, S)$-ketamine or $(S)$-ketamine in humans $[33,34,61]$. Preclinical data show that abuse liability of $(R, S)$-ketamine in humans is primarily due to the pharmacological effects of $(S)$-ketamine, but not $(R)$-ketamine $[23,27,35]$. Thus, it seems that $(R)$ ketamine is safer than $(R, S)$-ketamine or $(S)$-ketamine in humans. We recently reported that PCP-induced cognitive deficits in mice were ameliorated by subsequent repeated intermittent administration of $(R)$-ketamine $(10 \mathrm{mg} / \mathrm{kg} /$ day, twice weekly for 2-weeks), but not $(S)$-ketamine [46]. Taken together, it is likely that $(R)$-ketamine would be a potential prophylactic drug for schizophrenia when it can be used in subjects with high-risk for psychosis.

It is suggested that the decrease of PV-positive cells in the PFC may be related to the pathogenesis of schizophrenia $[62,63]$. Study using postmortem brain samples showed that dendritic spine density in PFC of patients with schizophrenia was decreased compared with controls [64]. Previous studies have shown that prenatal poly(I:C) exposure altered dendritic morphology in the PFC of nonhuman primate MIA models [65]. In this study, we found that the reduced PV-immunoreactivity in the PrL of mPFC and reduced dendritic spine density of PrL of mPFC, CA3 and DG of the hippocampus from adult offspring after MIA was significantly ameliorated by subsequent repeated intermittent administration of $(R)$-ketamine $(10 \mathrm{mg} / \mathrm{kg} /$ day). Given the role of mPFC in cognitive function, it is noteworthy that $(R)$-ketamine could improve decreased $\mathrm{PV}$-immunoreactivity and dendritic spine density in the mPFC of offspring after MIA.

Depression is common in subjects at ultra-high risk for psychosis, and associated with extensive functional impairment [66]. A longitudinal study showed that persistent negative symptoms exist in youth at clinical high risk for psychosis, resulting in significant and persistent functional impairment [67]. Considering the therapeutic potential of $(R)$-ketamine in depression, it is likely that $(R)$-ketamine could be a therapeutic drug for depression in subjects at high risk for psychosis, resulting in improvement of functional impairment.
In conclusion, the present data suggest that repeated intermittent administration of $(R)$-ketamine during juvenile and adolescent stages could prevent the onset of cognitive deficits and the loss of PV-immunoreactivity in the PrL of mPFC, the decreased spine density in the PrL of mPFC, CA3 and DG of hippocampus from adult offspring after MIA. Therefore, it is possible that the use of $(R)$-ketamine in young subjects at high risk for psychosis may prevent conversion to psychosis from prodromal symptoms.

Acknowledgements This study was supported by grant from Japan Agency for Medical Research and Development (AMED) (to K.H., JP20dm0107119).

\section{Declarations}

Conflict of interest Dr. Hashimoto is the inventor of filed patent applications on "The use of $R$-ketamine in the treatment of psychiatric diseases", " $(S)$-norketamine and salt thereof as pharmaceutical", " $R$ ketamine and derivative thereof as prophylactic or therapeutic agent for neurodegeneration disease or recognition function disorder", "Preventive or therapeutic agent and pharmaceutical composition for inflammatory diseases or bone diseases", " $R$-ketamine and its derivatives as a preventive or therapeutic agent for a neurodevelopmental disorder", "Preventive or therapeutic agent and pharmaceutical composition for inflammatory diseases", and "TGF- $\beta 1$ in the treatment of depression" by the Chiba University. Dr. Hashimoto also declares that he has received research support and consultant from Dainippon Sumitomo, Otsuka, Taisho, Murakami Farm, and Perception Neuroscience. The other authors have no conflict of interest.

Open Access This article is licensed under a Creative Commons Attribution 4.0 International License, which permits use, sharing, adaptation, distribution and reproduction in any medium or format, as long as you give appropriate credit to the original author(s) and the source, provide a link to the Creative Commons licence, and indicate if changes were made. The images or other third party material in this article are included in the article's Creative Commons licence, unless indicated otherwise in a credit line to the material. If material is not included in the article's Creative Commons licence and your intended use is not permitted by statutory regulation or exceeds the permitted use, you will need to obtain permission directly from the copyright holder. To view a copy of this licence, visit http://creativecommons.org/licenses/by/4.0/.

\section{References}

1. Elvevåg B, Goldberg TE (2000) Cognitive impairment in schizophrenia is the core of the disorder. Crit Rev Neurobiol 14(1):21

2. Harvey PD (2014) What is the evidence for changes in cognition and functioning over the lifespan in patients with schizophrenia? J Clin Psychiatry 75(Suppl 2):34-38

3. Keefe RS (2014) The longitudinal course of cognitive impairment in schizophrenia: an examination of data from premorbid through posttreatment phases of illness. J Clin Psychiatry 75(Suppl 2):2-8

4. Fusar-Poli P, Deste G, Smieskova R, Barlati S, Yung AR, Howes O, Stieglitz RD, Vita A, McGuire P, Borgwardt S (2012) Cognitive functioning in prodromal psychosis: a meta-analysis. Arch Gen Psychiatry 69(6):562-571

5. Bora E, Murray RM (2014) Meta-analysis of cognitive deficits in ultra-high risk to psychosis and first-episode psychosis: do the 
cognitive deficits progress over, or after, the onset of psychosis? Schizophr Bull 40(4):744-755

6. Mollon J, Reichenberg A (2018) Cognitive development prior to onset of psychosis. Psychol Med 48(3):392-403

7. Hauser M, Zhang JP, Sheridan EM, Burdick KE, Mogil R, Kane JM, Auther A, Carrión RE, Cornblatt BA, Correll CU (2017) Neuropsychological test performance to enhance identification of subjects at clinical high risk for psychosis and to be most promising for predictive algorithms for conversion to psychosis: a metaanalysis. J Clin Psychiatry 78(1):e28-e40

8. Hashimoto K (2019) Recent advances in the early intervention in schizophrenia: Future direction from preclinical findings. Curr Psychiatry Rep 21(8):75

9. Brown AS, Derkits EJ (2010) Prenatal infection and schizophrenia: a review of epidemiologic and translational studies. Am J Psychiatry 167(3):261-280

10. Brown AS, Meyer U (2018) Maternal immune activation and neuropsychiatric illness: a translational research perspective. Am J Psychiatry 175(11):1073-1083

11. Conway F, Brown AS (2019) Maternal immune activation and related factors in the risk of offspring psychiatric disorders. Front Psychiatry 10:430

12. Zuckerman L, Weiner I (2005) Maternal immune activation leads to behavioral and pharmacological changes in the adult offspring. J Psychiatr Res 39(3):311-323

13. Ozawa $\mathrm{K}$, Hashimoto $\mathrm{K}$, Kishimoto T, Shimizu E, Ishikura H, Iyo M (2006) Immune activation during pregnancy in mice leads to dopaminergic hyperfunction and cognitive impairment in the offspring: a neurodevelopmental animal model of schizophrenia. Biol Psychiatry 59(6):546-554

14. Yoshimi N, Futamura T, Hashimoto K (2013) Prenatal immune activation and subsequent peripubertal stress as a new model of schizophrenia. Expert Rev Neurother 13(7):747-750

15. Meyer U (2014) Prenatal poly(I:C) exposure and other developmental immune activation models in rodent systems. Biol Psychiatry 75(4):307-315

16. Meyer U (2019) Neurodevelopmental resilience and susceptibility to maternal immune activation. Trends Neurosci 41(11):793-806

17. Haddad FL, Patel SV, Schmid S (2020) Maternal immune activation by poly I: $\mathrm{C}$ as a preclinical model for neurodevelopmental disorders: a focus on autism and schizophrenia. Neurosci Biobehav Rev 113:546-567

18. Fujita Y, Ishima T, Hashimoto K (2016) Supplementation with D-serine prevents the onset of cognitive deficits in adult offspring after maternal immune activation. Sci Rep 6:37261

19. Han M, Zhang JC, Yao W, Yang C, Ishima T, Ren Q, Ma M, Dong C, Huang XF, Hashimoto K (2016) Intake of 7,8-dihydroxyflavone during juvenile and adolescent stages prevents onset of psychosis in adult offspring after maternal immune activation. Sci Rep 6:36087

20. Matsuura A, Ishima T, Fujita Y, Iwayama Y, Hasegawa S, Kawahara-Miki R, Maekawa M, Toyoshima M, Ushida Y, Suganuma H, Kida S, Yoshikawa T, Iyo M, Hashimoto K (2018) Dietary glucoraphanin prevents the onset of psychosis in the adult offspring after maternal immune activation. Sci Rep 8(1):2158

21. Ma M, Ren Q, Yang J, Zhang K, Xiong Z, Ishima T, Pu Y, Hwang SH, Toyoshima M, Iwayama Y, Hisano Y, Yoshikawa T, Hammock BD, Hashimoto K (2019) Key role of soluble epoxide hydrolase in the neurodevelopmental disorders of offspring after maternal immune activation. Proc Natl Acad Sci USA 116(14):7083-7088

22. Zhang JC, Li SX, Hashimoto K (2014) $R$ (-)-ketamine shows greater potency and longer lasting antidepressant effects than $S$ (+)-ketamine. Pharmacol Biochem Behav 116:137-141

23. Yang C, Shirayama Y, Zhang JC, Ren Q, Yao W, Ma M, Dong C, Hashimoto K (2015) $R$-ketamine: a rapid-onset and sustained antidepressant without psychotomimetic side effects. Transl Psychiatry 5:e632.

24. Yang C, Qu Y, Abe M, Nozawa D, Chaki S, Hashimoto K (2017) $(R)$-ketamine shows greater potency and longer lasting antidepressant effects than its metabolite $(2 R, 6 R)$-hydroxynorketamine. Biol Psychiatry 82(5):e43-e44

25. Fukumoto K, Toki H, Iijima M, Hashihayata T, Yamaguchi JI, Hashimoto K, Chaki S (2017) Antidepressant potential of $(R)$ ketamine in rodent models: comparison with $(S)$-ketamine. J Pharmacol Exp Ther 361(1):9-16

26. Yang C, Ren Q, Qu Y, Zhang JC, Ma M, Dong C, Hashimoto K (2018) Mechanistic target of rapamycin-independent antidepressant effects of $(R)$-ketamine in a social defeat stress model. Biol Psychiatry 83(1):18-28

27. Chang L, Zhang K, Pu Y, Qu Y, Wang SM, Xiong Z, Ren Q, Dong C, Fujita Y, Hashimoto K (2019) Comparison of antidepressant and side effects in mice after intranasal administration of $(R, \mathrm{~S})$ ketamine, (R)-ketamine, and (S)-ketamine. Pharmacol Biochem Behav 181:53-59

28. Zhang K, Yang C, Chang L, Sakamoto A, Suzuki T, Fujita Y, Qu Y, Wang S, Pu Y, Tan Y, Wang X, Ishima T, Shirayama Y, Hatano M, Tanaka KF, Hashimoto K (2020) Essential role of microglial transforming growth factor- $\beta 1$ in antidepressant actions of $(R)$-ketamine and the novel antidepressant TGF- $\beta 1$. Transl Psychiatry 10(1):32

29. Yang C, Han M, Zhang JC, Ren Q, Hashimoto K (2016) Loss of parvalbumin-immunoreactivity in mouse brain regions after repeated intermittent administration of esketamine, but not $R$-ketamine. Psychiatry Res 239:281-283

30. Hashimoto K, Kakiuchi T, Ohba H, Nishiyama S, Tsukada H (2017) Reduction of dopamine $\mathrm{D}_{2 / 3}$ receptor binding in the striatum after a single administration of esketamine, but not $R$-ketamine: a PET study in conscious monkeys. Eur Arch Psychiatry Clin Neurosci 267(2):173-176

31. Tian Z, Dong C, Fujita A, Fujita Y, Hashimoto K (2018) Expression of heat shock protein HSP-70 in the retrosplenial cortex of rat brain after administration of $(R, \mathrm{~S})$-ketamine and (S)-ketamine, but not (R)-ketamine. Pharmacol Biochem Behav 172:17-21

32. Tan Y, Hashimoto K (2020) Risk of psychosis after repeated intermittent administration of $(S)$-ketamine, but not $(R)$-ketamine, in mice. J Affect Disord 269:198-200

33. Vollenweider FX, Leenders KL, Oye I, Hell D, Angst J (1997) Differential psychopathology and patterns of cerebral glucose utilisation produced by $(S)$ - and $(R)$-ketamine in healthy volunteers using positron emission tomography (PET). Eur Neuropsychopharmacol 7:25-38

34. Leal GC, Bandeira ID, Correia-Melo FS, Telles M, Mello RP, Vieira F, Lima CS, Jesus-Nunes AP, Guerreiro-Costa LNF, Marback RF, Caliman-Fontes AT, Marques BLS, Bezerra MLO, DiasNeto AL, Silva SS, Sampaio AS, Sanacora G, Turecki G, Loo C, Lacerda ALT, Quarantini LC (2021) Intravenous arketamine for treatment-resistant depression: open-label pilot study. Eur Arch Psych Clin Neurosci 271(3):577-583

35. Bonaventura J, Lam S, Carlton M, Boehm MA, Gomez JL, Solís O, Sánchez-Soto M, Morris PJ, Fredriksson I, Thomas CJ, Sibley DR, Shaham Y, Zarate CA Jr, Michaelides M (2021) Pharmacological and behavioral divergence of ketamine enantiomers: implications for abuse liability. Mol Psychiatry. https://doi.org/ 10.1038/s41380-021-01093-2

36. Hashimoto K (2019) Rapid-acting antidepressant ketamine, its metabolites and other candidates: a historical overview and future perspective. Psychiatry Clin Neurosci 73(10):613-627

37. Yang C, Yang J, Luo A, Hashimoto K (2019) Molecular and cellular mechanisms underlying the antidepressant effects of ketamine enantiomers and its metabolites. Transl Psychiatry 9(1):280 
38. Zhang K, Hashimoto K (2019) An update on ketamine and its two enantiomers as rapid-acting antidepressants. Expert Rev Neurother 19:83-92

39. Wei Y, Chang L, Hashimoto K (2020) A historical review of antidepressant effects of ketamine and its enantiomers. Pharmacol Biochem Behav 190:172870.

40. Hashimoto K (2020) Molecular mechanisms of the rapid-acting and long-lasting antidepressant actions of $(R)$-ketamine. Biochem Pharmacol 177:113935.

41. Wei Y, Chang L, Hashimoto K (2021) Molecular mechanisms underlying the antidepressant actions of arketamine: beyond the NMDA receptor. Mol Psychiatry. https://doi.org/10.1038/ s41380-021-01121-1

42. Javitt DC, Zukin SR (1991) Recent advances in the phencyclidine model of schizophrenia. Am J Psychiatry 148(10):1301-1308

43. Domino EF, Luby ED (2012) Phencyclidine/schizophrenia: one view toward the past, the other to the future. Schizophr Bull 38(5):914-919

44. Hashimoto K, Malchow B, Falkai P, Schmitt A (2013) Glutamate modulators as potential therapeutic drugs in schizophrenia and affective disorders. Eur Arch Psychiatry Clin Neurosci 263(5):367-377

45. Hashimoto K (2014) Targeting of NMDA receptors in new treatments for schizophrenia. Expert Opin Ther Targets 18(9):1049-1063

46. Tan Y, Fujita Y, Qu Y, Chang L, Pu Y, Wang S, Wang X, Hashimoto $K$ (2020) Phencyclidine-induced cognitive deficits in mice are ameliorated by subsequent repeated intermittent administration of $(R)$-ketamine, but not $(S)$-ketamine: Role of BDNF-TrkB signaling. Pharmacol Biochem Behav 188:172839.

47. Fujita A, Fujita Y, Pu Y, Chang L, Hashimoto K (2020) MPTPinduced dopaminergic neurotoxicity in mouse brain is attenuated after subsequent intranasal administration of $(R)$-ketamine: a role of TrkB signaling. Psychopharmacology 237(1):83-92

48. Hashimoto K (2020) Brain-derived neurotrophic factor -TrkB signaling and the mechanism of antidepressant activity by ketamine in mood disorders. Eur Arch Psychiatry Clin Neurosci 270:137-138

49. Fujita Y, Hashimoto Y, Hashimoto H, Chang L, Hashimoto K (2021) Dextran sulfate sodium-induced inflammation and colitis in mice are ameliorated by $(R)$-ketamine, but not $(S)$-ketamine: A role of TrkB signaling. Eur J Pharmacol 897:173954

50. Qu Y, Shan J, Wang S, Chang L, Pu Y, Wang X, Tan Y, Yamamoto M, Hashimoto K (2021) Rapid-acting and long-lasting antidepressant-like action of $(R)$-ketamine in Nrf2 knock-out mice: a role of TrkB signaling. Eur Arch Psychiatry Clin Neurosci 271(3):439-446

51. Cazorla M, Prémont J, Mann A, Girad N, Kellendonk C, Rognan D (2011) Identification of a low-molecular weight TrkB antagonist with anxiolytic and antidepressant activity in mice. J Clin Invest 121:1846-1857

52. Ren Q, Ma M, Yang C, Zhang JC, Yao W, Hashimoto K (2015) BDNF-TrkB signaling in the nucleus accumbens shell of mice has key role in methamphetamine withdrawal symptoms. Transl Psychiatry 5:e666

53. Zhang JC, Yao W, Dong C, Yang C, Ren Q, Ma M, Han M, Hashimoto K (2015) Comparison of ketamine, 7,8-dihydroxyflavone, and ANA-12 antidepressant effects in the social defeat stress model of depression. Psychopharmacology 232:4325-4335

54. Zhang JC, Wu J, Fujita Y, Yao W, Ren Q, Yang C, Li SX, Shirayama Y, Hashimoto K (2014) Antidepressant effects of TrkB ligands on depression-like behavior and dendritic changes in mice after inflammation. Int J Neuropsychopharmacol 18: pyu077

55. Fujita Y, Fujita A, Ishima T, Hirai A, Suzuki S, Suganuma H, Hashimoto K (2020) Dietary intake of glucoraphanin during pregnancy and lactation prevents the behavioral abnormalities in the offspring after maternal immune activation. Neuropsychopharmacol Rep 40(3):268-274

56. Qu Y, Yang C, Ren Q, Ma M, Dong C, Hashimoto K (2018) Regional differences in dendritic spine density confer resilience to chronic social defeat stress. Acta Neuropsychiatr 30(2):117-122

57. Zhang J, Qu Y, Chang L, Pu Y, Hashimoto K (2019) (R)-ketamine rapidly ameliorates the decreased spine density in the medial prefrontal cortex and hippocampus of susceptible mice after chronic social defeat stress. Int J Neuropsychopharmacol 22:675-679

58. Domino EF (2010) Taming the ketamine tiger, 1965. Anesthesiology 113(3):678-684

59. Krystal JH, Karper LP, Seibyl JP, Freeman GK, Delaney R, Bremner JD, Heninger GR, Bowers MB Jr, Charney DS (1994) Subanesthetic effects of the noncompetitive NMDA antagonist, ketamine, in humans. Psychotomimetic, perceptual, cognitive, and neuroendocrine responses. Arch Gen Psychiatry 51(3):199-214.

60. Gill H, Gill B, Rodrigues NB, Lipsitz O, Rosenblat JD, El-Halabi S, Nasri F, Mansur RB, Lee Y, McIntyre RS (2021) The effects of ketamine on cognition in treatment-resistant depression: a systematic review and priority avenues for future research. Neurosci Biobehav Rev 120:78-85

61. Singh JB, Fedgchin M, Daly E, Xi L, Melman C, De Bruecker G, Tadic A, Sienaert P, Wiegand F, Manji H, Drevets WC, Van Nueten L (2016) Intravenous esketamine in adult treatment-resistant depression: a double-blind, double-randomization, placebocontrolled study. Biol Psychiatry 80(6):424-431

62. Gonzalez-Burgos G, Cho RY, Lewis DA (2015) Alterations in cortical network oscillations and parvalbumin neurons in schizophrenia. Biol Psychiatry 77(12):1031-1040

63. Dienel SJ, Lewis DA (2019) Alterations in cortical interneurons and cognitive function in schizophrenia. Neurobiol Dis 131:104208.

64. Konopaske GT, Lange N, Coyle JT, Benes FM (2014) Prefrontal cortical dendritic spine pathology in schizophrenia and bipolar disorder. JAMA Psychiat 71(12):1323-1331

65. Weir RK, Forghany R, Smith SE, Patterson PH, McAllister AK, Schumann CM, Bauman MD (2015) Preliminary evidence of neuropathology in nonhuman primates prenatally exposed to maternal immune activation. Brain Behav Immun 48:139-146

66. Schirmbeck F, van der Burg NC, Blankers M, Vermeulen JM, McGuire P, Valmaggia LR, Kempton MJ, van der Gaag M, Riecher-Rössler A, Bressan RA, Barrantes-Vidal N, Nelson B, Amminger GP, McGorry P, Pantelis C, Krebs MO, Ruhrmann S, Sachs G, Rutten BPF, van Os J, Nordentoft M, Glenthøj B; EU-GEI High Risk Study Group Authors, Fusar-Poli P, de Haan L (2021) Impact of comorbid affective disorders on longitudinal clinical outcomes in individuals at ultra-high risk for psychosis. Schizophr Bull 2021 Aug 21:sbab088. https://doi.org/10.1093/ schbul/sbab088

67. Devoe DJ, Lu L, Cannon TD, Cadenhead KS, Cornblatt BA, McGlashan TH, Perkins DO, Seidman LJ, Tsuang MT, Woods SW, Walker EF, Mathalon DH, Bearden CE, Addington J (2021) Persistent negative symptoms in youth at clinical high risk for psychosis: a longitudinal study. Schizophr Res 227:28-37 